\title{
Perigastric fluid collection after endoscopic sleeve gastroplasty
}
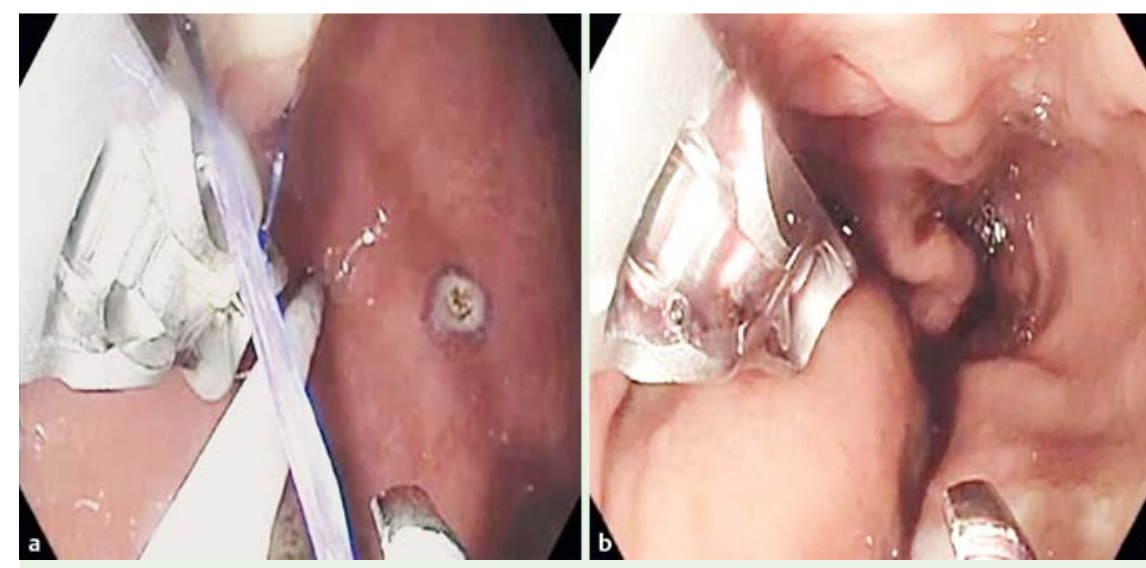

Fig. 1 Endoscopic views showing: a the technique used to perform endoscopic sleeve gastroplasty (ESG); $\mathbf{b}$ the appearance after completion of the ESG procedure.

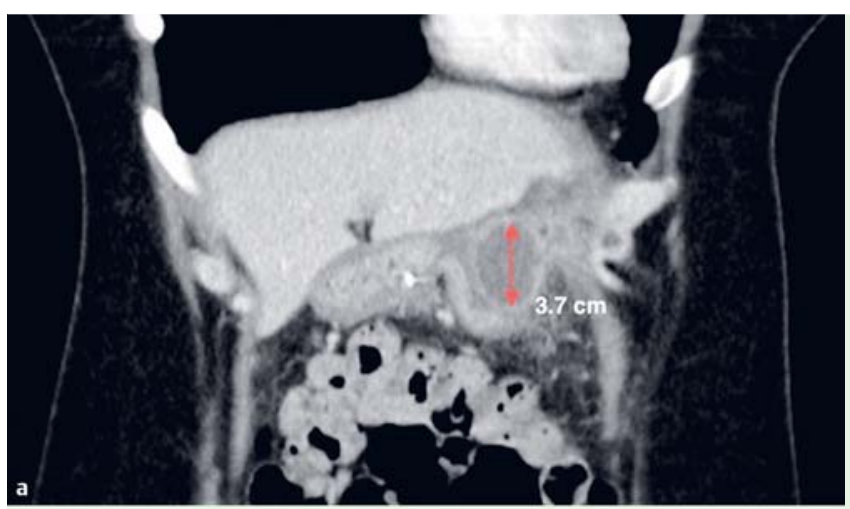

Fig. 2 Computed tomography (CT) scan of the abdomen with intravenous contrast 12 days post-endoscopic sleeve gastroplasty: a on coronal view, showing a rimenhancing $3.3 \times 3.7-\mathrm{cm}$ collection; $\mathbf{b}$ on axial view, showing a rimenhancing $3.3 \times 2.9-\mathrm{cm}$ collection.

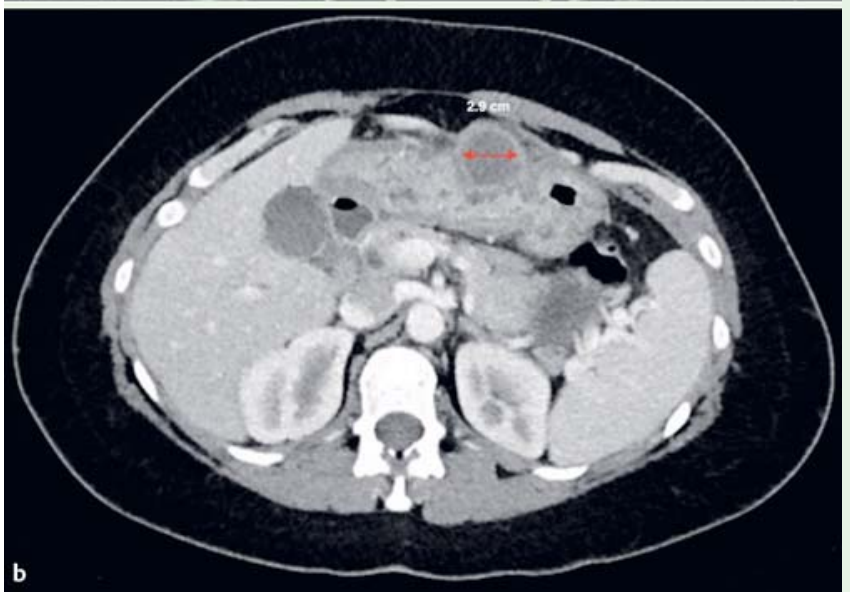

A 39-year-old woman with a body mass index (BMI) of $32 \mathrm{~kg} / \mathrm{m}^{2}$ was evaluated for suitability for endoscopic management of her obesity. Because of her interest in a durable weight loss intervention, she elected to undergo an endoscopic sleeve gastroplasty (ESG). The procedural details have been described previously by Sha- raiha et al. and Lopez Nava et al. [1-3]. In brief, the volume of the stomach is reduced by approximately $70 \%$ using a fullthickness endoscopic suturing system (OverStitch; Apollo Endosurgery, Austin, Texas, USA) ( $\bullet$ Fig. 1 ).

The patient recovered well in the days immediately after the procedure but pre- sented with gradual onset vomiting and abdominal pain 12 days after her ESG. An erect abdominal radiograph showed a non-obstructive bowel gas pattern without any evidence of free gas. An abdominal contrast-enhanced computed tomography $(\mathrm{CT})$ scan revealed a rim-enhancing $3.3 \times 2.9 \times 3.7-\mathrm{cm}$ fluid collection in the fundus along the greater curvature of the stomach, suggestive of a perigastric collection, with surrounding stranding of the omental fat ( Fig. 2).

She did not have fever or chills, and her vital signs were stable, with a normal temperature and a white blood cell (WBC) count of $11.1 \times 10^{3} / \mu \mathrm{L}$. The patient was given a stat dose of intravenous etrapenem and was discharged with oral ciprofloxacin $500 \mathrm{mg}$ twice daily and metronidazole $400 \mathrm{mg}$ three times daily for 7 days. At follow-up 3 weeks later, her symptoms had completely resolved and follow-up imaging revealed no residual collection.

There has only been one documented case of perigastric inflammatory serous fluid collection after ESG (adjacent to the fundus), which resolved with percutaneous drainage and antibiotics [4]. One possible cause of the perigastric fluid collection may be intractable vomiting causing a small leak along the thin-walled fundus. When such a collection is identified, we recommend initial conservative therapy with oral antibiotics if there are no signs or symptoms of sepsis. Depending on the size and location of the collection, percutaneous drainage could be performed.

\section{Endoscopy_UCTN_Code_CPL_1AH_2AJ}

Competing interests: Mouen A. Khashab is a consultant for Boston Scientific and Olympus America and has received research support from Cook Medical.

Vivek Kumbhari is a consultant for Boston Scientific and Apollo Endosurgery. All other authors have no disclosures

\section{Sindhu Barola ${ }^{1}$, Abhishek Agnihotri ${ }^{2}$, Mouen A. Khashab ${ }^{1}$, Vivek Kumbhari ${ }^{1}$}

${ }^{1}$ Department of Medicine and Division of Gastroenterology and Hepatology, The Johns Hopkins Medical Institutions, Baltimore, Maryland, USA

2 Department of Medicine, Johns Hopkins University School of Medicine, Baltimore, Maryland, USA 


\section{References}

1 Sharaiha RZ, Kedia P, Kumta $N$ et al. Initial experience with endoscopic sleeve gastroplasty: technical success and reproducibility in the bariatric population. Endoscopy 2015; 47: 164-166

2 Lopez-Nava G, Galvao M, Bautista-Castaño I et al. Endoscopic sleeve gastroplasty with 1-year follow-up: factors predictive of success. Endosc Int Open 2016; 4: E222 - E227

3 Lopez-Nava G, Galvão MP, da Bautista-Castaño I et al. Endoscopic sleeve gastroplasty for the treatment of obesity. Endoscopy 2015; 47: 449-452

4 Abu Dayyeh BK, Acosta A, Camilleri M et al. Endoscopic sleeve gastroplasty alters gastric physiology and induces loss of body weight in obese individuals. Clin Gastroenterol Hepatol. Epub ahead of print 2015 Dec 31

\section{Bibliography}

DOI http://dx.doi.org/

10.1055/s-0042-117844

Endoscopy 2016; 48: E340-E341

(c) Georg Thieme Verlag KG

Stuttgart · New York

ISSN 0013-726X

\section{Corresponding author}

Vivek Kumbhari, MD

Division of Gastroenterology and Hepatology Johns Hopkins Medical Institutions

4940 Eastern Avenue

AA Building, 3rd floor

Baltimore

Maryland 21224

USA

Fax: +1-410-550-7861

vkumbhari@gmail.com 